\title{
ILLINOIS INSTITUTE OF TECHNOLOGY
}

\section{CRYOGENIC THERMOMETRY - METHODS AND INSTRUMENTATION}

BY

\author{
RICHARD FRANCIS KOCH
}

Submitted in.Partial Fulfillment of the Requirements Eor the Degree of Master of Science in Physics in the Graduate School of Illinois Institute of Technology

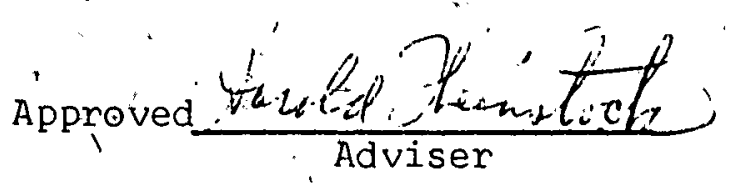




\section{DISCLAIMER}

This report was prepared as an account of work sponsored by an agency of the United States Government. Neither the United States Government nor any agency Thereof, nor any of their employees, makes any warranty, express or implied, or assumes any legal liability or responsibility for the accuracy, completeness, or usefulness of any information, apparatus, product, or process disclosed, or represents that its use would not infringe privately owned rights. Reference herein to any specific commercial product, process, or service by trade name, trademark, manufacturer, or otherwise does not necessarily constitute or imply its endorsement, recommendation, or favoring by the United States Government or any agency thereof. The views and opinions of authors expressed herein do not necessarily state or reflect those of the United States Government or any agency thereof. 


\section{DISCLAIMER}

Portions of this document may be illegible in electronic image products. Images are produced from the best available original document. 


\section{ILLINOIS INSTITUTE OF TECHNOLOGY}

LE G A L N O T I C E
This report was prepared as an account of Government sponsored work, Neither the United
States, nor the Commission, nor any person acting on behalf of the Commission:
A, Makes any warranty or representation, expressed or impled, whth respect to the accu-
racy, completeness, or usefulness of the information contained in thls report, or that the use
of any information, apparatus, method, or process disclosed in thls report may not infringe
privately owned rights; or
B. Assumes any liabilitles with respect to the use of, or for damages resulting from the
use of any tnformation, apparatus, method, or process disclosed in this report.
As used in the above, "pperson acting on behalf of the Commission" includes any em-
ployee or contractor of the Commission, or employee of such contractor, to the extent that
such employee or contractor of the Commission, or employee of such coniractor prepares,
disseminates, or provides access to, any information pursuant to his employment or contract
with the Commission, or his employment with such contractor.

CRYOGENIC THERMOMETRY - METHODS AND INSTRUMENTATION

BY

RICHARD FRÄNCIS KOCH

Submitted in Partial Fulfillment of the Requirements for the Degree of Master of Science in Physics

in the Graduate School of Illinois Institute of Technology

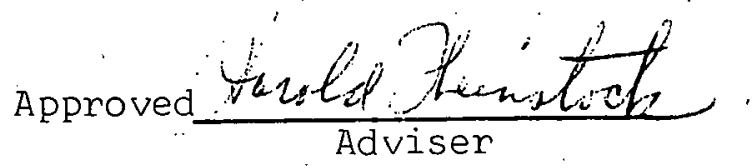

\footnotetext{
CHICAGO, ILLINOIS
}

. June, 1968 


\section{PREFACE}

The object of many experiments in low temperature physics is the measurement of some physical or thermodynamic property of a substance as a function of temperature. Such measurements are often of theoretical interest because at very low temperatures, quantum-mechanical effect's become large enough so that the results predicted by classical statistical mechanics are not obtained. Thus, low temperature/experiments provide a means of testing quantum-mechanical theories of the structure of solids or liquids. Since theory will usually predict some specific temperature dependence of a physical property, the ability to measure temperature accurately is an important requirement in carrying out these experiments.

This thesis will first review temperature scales and measurements in general, and then describe specific methods and apparatus constructed and used for thermometry in the liquid helium temperature range in the Low/ Temperature Laboratory at IIT.

This dissertation is indebted to my adviser, Dr. Harold Weinstock; for his overall guidance, and also to Raymond Guenther and Dr. Arthur Harris for many helpful suggestions for carrying out the laboratory work involved. The financial support of the United States Atomic Energy Commission is also gratefully acknowledged .*

* Supported in part under Contract AT(11-1)-1629, Division of Research, U.S.A.E.C. 
PREFACE .......................

I. INTRODUCTION; TEMPERATURE SCALES AND STANDARDS.

Absolute Thermodynamic Temperature Scale

Ideal Gas Temperature Scale

International Practical Temperature Scale

Helium Vapor Pressure Temperature Scales

II. THE PARAMAGNETIC SUSCEPTIBILITY THERMOMETER.

Basic Principles of Magnetic Thermometry

Preparation of CMN Samples for Susceptibility Measurements Apparatus for Calibration of

Resistance Thermometers Mutual Inductance Bridge Results

III. RESISTANCE THERMOMETRY AT LIQUID HELIUM TEMPERATURES...........

Characteristics of Low Temperature Resistance Thermometers

Resistance Measuring Circuits

Some Results Using Carbon Composition Resistance Thermometers

BIBLIOGRAPHY $\ldots \ldots \ldots \ldots \ldots \ldots \ldots \ldots \ldots \ldots \ldots$ 


\section{LIST OF ILLUSTRATIONS}

Figure

1. Cross Sectional View of Cryostat Containing Apparatus for Magnetic Susceptibility Measurements................. 24

2. Mutual Inductance Bridge Circuit...........

3. Calibration Points: Mutual Inductance vs $\cdot \mathrm{He}^{3}$ Vepor Pressure Temperature..........

4. A. C. Wheatstone Bridge Circuit...........

5. Resistance vs. Temperature Calibration Curve for $1 / 10$ watt Carbon Composition Resistor, 12 Ohms Nominal Resistance...

6. Resistance vs. Temperature Calibration Curve for $1 / 10$ watt Carbon Composition Resistor, 68 Ohms Nominal Resistance.. 


\section{INTRODUCTION: TEMPERATURE-SCALES AND ST'ANDARDS}

\section{Absolute Thermodynamic Temperature Scale}

The basic or fundamental temperature scale of scientific work, to which all temperature measurements are ultimately referred: is the absolute thermodynamic scale. Such a temperature scale was first proposed by Kelvin over one hundred years ago is one that would be universal and independent of the characteristics of individual thermometric property or thermodynamic system used.

The absolute thermodynamic scale was originally defined in terms of the reversible Carnot heat engine cycle, a set of processes that can, in principle, be performed with any thermodynamic system. The system is imagined first to be in thermal equilibrium with a cold reservoir at a fixed temperature $t_{2}$, as measured on any arbitrary temperature scale. The following four processes then performed reversibly, that is, quasi-statically, in order constitute the Carnot cycle:

1. Work is done on the system adiabatically so that its temperature rises to a higher value $t_{1}$.

2. The system is maintained in contact with a heat reservoir at temperature $t_{1}$, and an isothermal process is performed so that a quantity of heat $Q_{1}$ is absorbed from the reservoir.

3. An adiabatic process is performed in a direction opposite to 1. until the temperature drops back to $t_{2}$.

4. The system is maintained in contact with the reservoir at $t_{2}$; and an isothermal process is performed in a direction opposite to 2. until the system has returned to its original state. 
During this process, heat $\mathrm{Q}_{2}$ is rejected to the cold reservoir. The ratio of the temperatures $\mathrm{T}_{1}$ and $\mathrm{T}_{2}$ of the hot and cold reservoirs respectively on the thermodynamic scale is defined as equal to the ratio of the quantities of heat transferred at these temperatures by the system undergoing the Carnot cycle, that is:

$$
\frac{\mathrm{T}_{1}}{\mathrm{~T}_{2}}=\frac{Q_{1}}{Q_{2}}
$$

For a more detailed explanation of the thermodynamic temperature scale, or for definition of terms used here, the reader is referred to any standard textbook on thermodynamics, such as Zemansky ( 1 \% .

The definition of the thermodynamic temperature scale gives only the ratio of two temperatures and not a numerical value for any one temperature. However, by assigning a value to one point on the scale, the values of all other points will be determined. The thermodynamic Kelvin scale was defined in this way by international agreement in 1954, when the value $273.16^{\circ} \mathrm{K}$ was assigned to the triple point of water, which is the unique point of temperature and pressure where all three phases can coexist in equilibrium. (the triple point pressure is 4.58 torr.) Before 1954, there had been two defined points; the normal boiling point and ice point of water. The Celsius temperature scale is defined in terms of the Kelvin scale by a simple shift of the zero point:

$$
T\left({ }^{\circ} \mathrm{C}\right)=T\left({ }^{\circ} \mathrm{K}\right)-273.15^{\circ}
$$

The thermodynamic temperature scale is a fundamental and uni"For all numbered references, see bibliography. 
versal scale because of its basic theoretical foundation and its independence of materials and experimental methods used. However. it is not a good working scale for laboratory measurements because it is based on idealizations which are approximated only with great difficulty experimentally. For instance, the requirement of adiabatic processes can never be completely realized; there will always be some finite heat leak between the system and its surroundings. Also, no real process is ever completely reversible, and the measurement of the quantity of heat given up by the system to its surroundings during an isothermal process can be very difficult to perform.

\section{Ideal Gas Temperature Scale}

A gas thermometer uses a fixed quantity of a gas in thermal equilibrium with another system to measure the temperature of that system. Usually, either the pressure P. on the volume $V$. of the gas is used as the thermometric property, and the other is held constant during the measurements. It was found that, in the limiting case of very low pressures; the temperatures determined by ali gas thermometers agreed, regardless of the gas used, or whether the thermometer was the constant pressure or constant volume type. The temperature scale determined this way is called the ideal gas temperature scale, and follows the ideal gas law

$$
\because \mathrm{PV}=\mathrm{nRt}
$$

where $R$ is the universal gas constant, and $n$ is the quantity of gas in moles used in the thermometer. The term "ideal gas" is used because the above equation may be derived from kinetic theory 
by assuming a gas made up of non-interacting point particles.

In order to find the relation between the ideal gas and the thermodynamic temperature scales, a quantity of an ideal gas going through a Carnot cycle is considered. In this case, processes 1 and 4 of the cycle as listed on page 1 are compressions of the ideal gas, and 2 and 3 are expansions. If the temperatures $t_{1}$ and $t_{2}$ of the hot and cold reservoirs are determined according to the ideal gas temperature scale, it can be shown that (I)

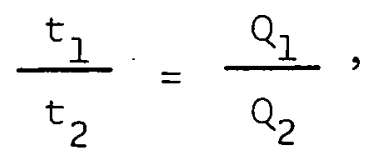

i.e., the ideal gas temperature is identical to the absolute thermodynamic temperature (as long as the same numerical value is assigned to one standard fixed point).

Thus, over the wide range of temperatures where it is possible to use a gas thermometer (…e., excluding both very high and very low temperatures), measurements on the thermodynamic temperature scale are in practice made using gas thermometers. The constant volume variety using helium gas is most often used, with a correction factor employed to effect the extrapolation to zero pressure. Gas thermometers, however, have several disadvantages which make them inconvenient for laboratory measurements in most cases. They are cumbersome, slow in coming to equilibrium, and cannot be read as precisely or accurately as some types of secondary thermometers which will be described below. International Practical Temperature Scale In order to provide a uniform scale for experimental use 
on which temperatures could be both converiently and accurately measured, standard temperature scales have been adopted by agreement. Such scales are defined in terms of measurements on some specified type of thermometer and are chosen so as to agree with the thermodynamic scale to within the best available measurements on the latter scale.

The most important of these standard scales is the International Practical Temperature Scale of 1948 adopted by the General Conference on Weights and: Measures in that year as a revision of the International Temperature Scale which had been adopted in 1927 (2,3). This scale has six defining fixed temperature points, and specified means for interpolation between these points.

The defining fixed points are the temperatures of the normal (standard'atmospheric pressure) boiling points (NBP) and normal melting points (NMP) of different materials, and of the ice point, the normal equilibrium point of ice and airsaturated water. Specificaliy, the six points are:

$$
\begin{array}{lc}
\text { NBP of oxygen } & -182.97^{\circ} \mathrm{C} \text { (Int. 1948) } \\
\text { ice point } & 0 \% \\
\text { NBP of water } & 100 \% \\
\text { NBP of sulfur } & 444.6^{\circ} \\
\text { NMP of silver } & 960.8^{\circ} \\
\text { NMP of gold } & 1063.0^{\circ}
\end{array}
$$

The values of temperature in the table above are considered exact by definition on the international practical Celsius scale, and all agree with the values for these points on the 
thermodynamic Celsius scale as measured by gas thermometry, to within the experimental error of these measurements. For each of these points, except the ice point, the experimental error in the determination of the point on the thermodynamic scale is considerably greater than the limit of precision with which it may be measured on the practical scale. For example, the sulfur point is not known to better than $\pm_{0.1^{\circ}}$ on the thermodynamic scale, but it is possible to reproduce this point with a platinum resistance thermometer as used for measurements on the practical scale to a precision of the order of $\pm_{0} .005^{\circ}$ or better (2).

The temperature interval from the NBP of oxygen to the NMP of gold is divided into three parts in defining the means for interpolating between the fixed points on the international practical scale.

Between $0^{\circ}$ and $630.5^{\circ} \mathrm{C}$, the scale is defined by the use of an electrical resistor made of platinum wire, with the temperature $t$ given by the equation

$$
R_{t}=R_{0}\left(1+A t+B t^{2}\right)
$$

$R_{t}$ is the measured resistance at any temperature $t$, and the constants $R_{O}, A$ and $B$.are determined for each resistance thermometer by measurements at the ice point, and at the normal boiling points of water and sulfur. The purity and physical condition of the platinum wire used in the resistance thermometers is controlled by the specification that the ratio of its electrical resistance at $100^{\circ} \mathrm{C}$ to that at $0^{\circ} \mathrm{C}$ must be not less than 1.3920 , (according to the 1960 revision of the international scale (3) ).

For the temperature range from $-182.97^{\circ} \mathrm{C}$ to $0^{\circ} \mathrm{C}$, the same 
platinum resistance thermometer is used, but the temperature. equation is modified to

$$
R_{t}=R_{0}\left[I+A t+B t^{2}+C(t-100) t^{3}\right] \text {, }
$$

with the additional constant $c$ determined by a measurement at the NBP of oxygen.

The scale from $630.5^{\circ} \mathrm{C}$ to $1063^{\circ} \mathrm{C}$ is defined by means of a 10\% rhodium-platinum against pure platinum thermocouple with the equation

$$
E=a+b t+c t^{2}
$$

giving the temperature in terms of the measured thermocouple voltage $\mathrm{E}$. The constants are determined by calibrations at the melting points of silver and gold, and against the platinum resistance thermometer at $630.5^{\circ} \mathrm{C}$. The platinum used in the thermocouple must meet the same purity specification as that for the resistance thermometer.

A standard optical pyrometer calibrated against the gold point at $1063^{\circ} \mathrm{C}$ is used to extrapolate the practical scale to higher temperatures, according to Planck's radiation law.

The international practical temperature scale does not extend below the oxygen point, $-182.97^{\circ} \mathrm{C}$ or $90.19^{\circ} \mathrm{K}$ (Int. 1948). The original international scale of 1927 had included an extrapolation by means of the platinum resistance thermometer to $-190^{\circ} \mathrm{C}$, but this extrapolation was found to be unreliable and was deleted in the 1948 revision (2). The reason the scale cannot be easily extended into this region is that, below $90^{\circ} \mathrm{K}$, it is impossible to express the resistance of platinum in a simple analytical form with a small number of constants which could be 
determined by measurements at a few fixed points such as normal boiling points (4). However, platinum resistance thermometers remain useful down to about $10^{\circ} \mathrm{K}$, but they must be individually calibrated point by point against a gas thermometer. The National Bureau of standards has, in fact, used a set of such calibrated resistance thermometers as its own standard for temperature calibration purposes in the range from $12^{\circ}$ to $90^{\circ} \mathrm{K}$, in agreement with the thermodynamic scale to within $\pm 0.02^{\circ}$, and a sufficiently high degree of stability and reproducibility $(5,6)$.

Carbon composition and germanium resistors are especially useful as secondary thermometers in this low temperature range, and can be used to much lower temperatures than the standard platinum thermometers, down to well below $1^{\circ} \mathrm{K}$. They must also be individually calibrated point by point against another thermometer. These thermometers will be discussed in some detail in Section III of this thesis. Thermocouples have also been used for temperature measurements below the oxygen point (5), but their efficiency drops off so that they are not useable below about $10^{\circ} \mathrm{K}$.

\section{Helium Vapor Pressure Temperature Scales}

Although there is no continous standard secondary or practical temperature scale below $90^{\circ} \mathrm{K}$, there is a scale of this kind below $5^{\circ} \mathrm{K}$. This is the helium vapor pressure temperature scale. The temperature at which the liquid and gaseous phases of a substance will both exist in equilibrium varies with the pressure on the gas or vapor phase. If a point by point calibration of vapor pressure against corresponding equilibrium temperature 
measured on the thermodynamic scale is once made for a pure substance, then, this calibration can be used as a universal, reproducible standard temperature scale. The scale is, in effect, a continuous series of fixed points similar to the normal boiling points used in the international practical scale.

A vapor pressure temperature scale is especially convenient

- in the case of helium, because liquid helium is almost universally used as the refrigerant for experiments within a few degrees of absolute zero, and the temperature is usually controlled by varying the pressure of the vapor over the liquid helium bath. The first standard helium vapor pressure temperature scale was adopted in 1948 by an informal agreement among the principal laboratories involved in setting up temperature standards. It was based on both theoretical considerations and on vapor pressure measurements compared to temperatures determined by both gas thermometers and paramagnetic susceptibility measurements (7). (Paramagnetic susceptibility is used as the primary thermometer on the thermodynamic scale at temperatures too low to permit the use of a gas thermometer. This subject will be discussed at length in section II of this thesis.) Subsequent measurements and corrections led to the revision of this helium vapor pressure scale yielding finally "the $1958 \mathrm{He}^{4}$ temperature scale" (8). The useful range of. this scale is from about 0.I torr, corresponding to $0.98^{\circ} \mathrm{K}$. to the critical point at 1718 torr and $5.206^{\circ} \mathrm{K}(7)$ : The scale 3 s used in the form of a calibration curve or table, as the temperature to vapor pressure relationship does not fit any simple algebraic function. 
There are two isotopes of helium, mass numbers 3 and 4, which have considerably different physical properties. The naturally occuring isotope, $\mathrm{He}^{4}$, is the one used in the vapor pressure temperature scale described in the preceeding paragraph. The lighter isotope is found only in a negligibly small concentration $(0.00013 \%)$ in naturally occurring helium, but the introduction of nuclear peactors has made it possible to produce $\mathrm{He}^{3}$ of high purity by nuclear transmutation. This process begins with the neutron irradiation of lithium;

$$
3^{\mathrm{Li}^{6}}+\mathrm{O}^{\mathrm{n}} \rightarrow 2^{\mathrm{He}}+{ }_{1} \mathrm{H}^{3} .
$$

The two gaseous products of this reaction are separated by allowing the tritium to diffuse through heated palladium, which is impermeable to the helium. Tritiun, $\mathrm{H}^{3}$, is radioactive with a half-life of 12.26 years, producing $\mathrm{He}^{3}$ by beta decay. The $\mathrm{He}^{3}$ is separated out by the heated palladium technique and further purified by freezing out impurities, which yields $\mathrm{He}^{3}$ gas with a maximum $\mathrm{He}^{4}$ content of less than 0.06\%. By 1950, the bulk physical properties of liquified $\mathrm{He}^{3}$ had been measured (9), and today, it is possible to use it as a refrigerant fluid, obtaining the coldest temperatures by cooling with a liquefied gas.

A $\mathrm{He}^{3}$ vapor pressure temperature scalè covering the interval from $0.31^{\circ} \mathrm{K}$, corresponding to 0.0015 torr, to $3.34^{\circ} \mathrm{K}$ and 886.0 torr has been published by Sydoriak and Roberts (10). Their scale is based in part on the earlier work of Abraham, Osborne, and Weinstock (9), who had made comparative measurements of the vapor pressures of $\mathrm{He}^{3}$ and $\mathrm{He}^{4}$ from $1.025^{\circ} \mathrm{K}$ to $3.35^{\circ} \mathrm{K}$ (the critical point of $\mathrm{He}^{3}$ ), and is extended below $1^{\circ} \mathrm{K}$ by calibration against 
magnetic susceptibility measurements on both ferric ammonium alum and chrome methylamine alum.

The upper limit on the temperature range of these helium vapor pressure scales is obviously the critical point, above which temperature the Iiquid phase can not exist regardless of the pressure. The lower limit of the useful range is effectively determined by practical considerations involving the thermomolecular pressure ratio, as will be explained below:

A vapor pressure thermometer uses a tube or pipe coming from a vessel at low temperature containing liquid helium to a manometer at room temperature where the pressure is measured. This difference in temperature between the two ends of the tube produces a difference between the measured pressure and the pressure at the surface of the liquid, where the gaseous and liquid phases are in equilibrium.

The ratio $\mathrm{p}_{\mathrm{C}} / \mathrm{P}_{\mathrm{w}}$ of the pressure at the cold end of the tube to that at the warm end is called the thermomolecular pressure ratio, and is a function of the relative dimensions of the inner radius of the tubing and the mean free paths of the gas molecules at the cold and warm ends of the tube. These ratios for He 3 and $\mathrm{He}^{4}$, based on theoretical calculations, and verified to some extent by experiment, have been tabulated by Roberts and Sydoriak (11) for different hot and cold temperatures and tubing radii. The ratio is unity at relatively high pressures and large tubing radii, but becomes increasingly smaller as the radius is made smaller, or as the pressure decreases (i.e., as the temperature of the cold end gets lower). For example, for 
a tube of $1 \mathrm{~mm}$ inside radius going from room temperature to a vessel containing liquid $\mathrm{He}^{3}, \mathrm{p}_{\mathrm{C}} / \mathrm{P}_{\mathrm{w}}$ is about 0.3 for $\mathrm{p}_{\mathrm{w}}$ equal to 0.02 torr (corresponding to a cold temperature of about $\left.0.4^{\circ} \mathrm{K}\right)$. The tabulated thermomolecular pressure ratio is at best an approximation, and, in this range, is extremely sensitive to very small changes in pressure or tubing size. Thus, it introduces a large uncertainty to any temperature measurement near the low end of the scale. This difficulty does not exist at higher temperatures because the ratio very quickly approaches unity as the pressure increases, e.g., for the $1 \mathrm{~mm}$ radius tubing of the previous example, $\mathrm{p}_{c} / \mathrm{p}_{\mathrm{W}}$ goes up to 0.97 if the pressure is increased to 1 torr (corresponding to a temperature between 0.6 and $\left.0.7^{\circ} \mathrm{K}\right)(10,11)$.

The $\mathrm{He}^{4}$ and $\mathrm{He}^{3}$ vapor pressure scales just described are used at the IIT Low Temperature Laboratory as temperature standards in their respective ranges for calibration of other types of thermometers. These calibrations wili/be described in the following sections of this thesis. 
Basic Principles of Magnetic Thermometry

Temperature Dependence of a Perfect Paramagnetic. In the region around $I^{\circ} K$ and below, the thermometric property which most closely approximates the absolute thermodynamic temperature scale is the magnetic susceptibility of certain paramagnetic salts. The situation is somewhat analogous to that of gas thermometry at higher temperatures in the following way: A simple functional dependence on absolute temperature is calculated for an idealized statistical system, and then real physical systems are found which approximate the ideal system closely enough under certain conditions that they follow the idealized temperature dependence to within the experimental accuracy

The idealized system which forms the analogue of the ideal gas in the magnetic case is the perfect paramagnetic consisting of $\mathrm{N}$ magnetic dipoles per unit volume, each of magnetic moment $\mu$. It is assumed that the dipoles do not interact with one another, so that the potential energy $V$ of each dipole is entirely due to its interaction with a uniform applied magnetic field $\underline{H}$, that is:

$$
V=-\underline{\mu} \cdot \underline{H} \cdot
$$

If the total energy of the system is distributed among the dipoles according to Boltzmann statistics, and, if the applied field $\underline{H}$ is small, so that

$$
\mu \mathrm{H} \ll k T,
$$

then the susceptibility $\mathbf{X}$ is given by the simple expression 


$$
x=\frac{M}{H}=\frac{N \mu^{2}}{3 k T}=\frac{C}{T}
$$

which is usually called Curie's Law, with the proportionality constant

$$
c=\frac{N \mu^{2}}{3 k}
$$

known as the Curie constant (12).

"Dilute" Magnetic Salts. The requirement of non-interacting dipoles may be approached in a system of atomic magnetic moments if the magnetic ions or molecules are separated by a relativejy. large distance from each other, much as the properties of an ideal gas are approached by a real gas as the interaction between the molecules is decreased by reducing the pressure.

Such "dilute" magnetic materials were first sought for magnetic cooling experiments. Atoms or ions with partly filled inner electron shells have magnetic moments of the right order of magnitude for this purpose. Trivalent ions of the rare earth elements ( $\mathrm{Ce}, \mathrm{Pr}, \mathrm{Nd}$, etc.) have a partially filled $4 \mathrm{f}$. shell; and atoms of the iron or transition group ( $\mathrm{Fe}, \mathrm{Cr}, \mathrm{Mn}$, $\dot{v}$, etc.) have an unfilled $3 d$ on next-to-outer shell, which becomes the outermost shell in the ionic state. Thus, the materials examined were mixed hydrated salts of these elements, in which the magnetic ions are separated by many other ions and water of crystalization molecules which themselves have zero magnetic moment. Certain of the alums, such as iron ammonium alum, $\mathrm{Fe}_{2}\left(\mathrm{SO}_{4}\right)_{3} \cdot\left(\mathrm{NH}_{4}\right)_{2} \mathrm{SO}_{4} \cdot 24 \mathrm{H}_{2} \mathrm{O}$, and chromic potassium alum, $\mathrm{Cr}_{2}\left(\mathrm{SO}_{4}\right)_{3} \cdot \mathrm{K}_{2} \mathrm{SO}_{4} \cdot 24 \mathrm{H}_{2} \mathrm{O}$, which utilize the magnetic moments of the ions $\mathrm{Fe}^{+++}$and $\mathrm{Cr}{ }^{+++}$, respectively, have been quite useful 
in magnetic cooling experiments, and their properties and those of several other similar salts have been studied extensively in this connection (13). However, from the standpoint of making magnetic temperature determinations alone, the most suitable of all the magnetic salts studied to date is cerium magnesium nitrate, $2 \mathrm{Ce}\left(\mathrm{NO}_{3}\right)_{3} \cdot 3 \mathrm{Mg}_{3}\left(\mathrm{NO}_{3}\right)_{2} \cdot 24 \mathrm{H}_{2} \mathrm{O}$, usually abbreviated CMN. This is the salt used in the thermometric apparatus described later in this section.

Determining The Relation Between Magnetic and Thermodynamic Temperature. What one does in practice, when using paramagnetic susceptibility as a thermometer, is to define a magnetic temperature $\mathrm{T} *$ for the particular material being used, in the form of a Curie's Law dependence:

$$
\mathrm{T} *=\frac{\mathrm{C}}{\mathrm{x}}
$$

The constant $C$ is now determined experimentally by measuring $x$ at two or more points where the thermodynamic temperature $T$ is known by other means. At these calibration points, $T *$ is taken to be equal to $T$, then, $T *$ is used in measuring temperatures in a range below that in which $\mathrm{T}$ can be determined by other means. Since one is now dealing with a real paramagnetic material, and not the idealized one described earlier, the relation between $T *$ and $\mathrm{T}$ is not known a priori, and must be experimentally determined in some way using the fundamental definition of $T$, or the laws of thermodynamics that follow from this definition. Once someone has done this satisfactorily for a given material, then other experimenters may make use of it as a primary temperature standard. 
$T$ is usually found in these cases by making use of the

relation

$$
\mathrm{T}=\frac{\mathrm{d} \mathrm{U}}{\mathrm{dS}},
$$

which results from combining the first and second laws of thermodynamics under conditions in which no work is done either on or by the system. In the case of a paramagnetic, this means that the applied field $H$ must be zero. If the internal energy $u$ and the entropy. $S$ are each known as a function of $T *$ for $H=0$, these two functions can be combined to give a U vs. S curve. For each point on this curve, the value of $T *$ is known by the supposi- . tion just above, and the value of $T$ is also known, since it equals the slope of the curve at that point. Thus, a set of corresponding values of $T$ and $T *, \underline{i . e}$, the functional dependence of $T$ on $T *$, would be found. In the next few paragraphs, methods will be outlined for determining the necessary $U$ vs. $T *$ and $S$ vs. $T *$ relationships.

The relation between $\mathrm{U}$ and $\mathrm{T} *$ is usually found by integrating its derivative, the magnetic specific heat

$$
\mathrm{C}^{*}=\left(\frac{\mathrm{dU}}{\mathrm{d} \mathrm{T}^{2}}\right)_{\mathrm{H}=0}
$$

$C *$ as a function of $T *$ may be determined in the following manner:

A large field $\mathrm{H}$ is first applied isothermally to a sample of the paramagnetic material at a known thermodynamic temperature $T_{i}$. Then, the sample is thermally isolated, and $H$ is reduced to zero adiabatically, causing $\mathrm{T}$ (and $\mathrm{T} *$ ) to decrease. (This is the principle of cooling by adiabatic demagnetization.) Next, heat is added at a known rate dQ/dt, and the corresponding warming rate $\mathrm{dT} \% / \mathrm{dt}$, (in general, a non-constant function of the 
time $t$ ), is noted. Because no work is done, $d u=d Q$, and $C^{*}$ may be obtained by eliminating the parameter $t$ between $\mathrm{dQ} / \mathrm{dt}$ and $\mathrm{dT} * / \mathrm{dt}$

The heat added in the last step of the above procedure may be introduced by conduction from an electric heating coil in thermal contact with the salt sample, or by irradiating the sample with gamma rays from a radioisotope source causing heating by the absorption of the gammas in the material. The gamma irradiation method was introduced to give more uniform heating throughout the entire volume of the sample (14), but the rate of heating cannot be known as precisely this way.

In an actual experiment of this kind, it is found that the sample warms up or "drifts" toward higher temperatures even when no heat is being added intentionally, because it is impossible in practice to isolate completely the sample thermally from its surroundings. One corrects $\mathrm{dT} \% \mathrm{dt}$ for the effect of this unintentional heat leak by periodically switching the applied heat on and off. In this way the heating rate due to the heat leak alone may also be determined and subtracted from the total heating rate to give the value of $\mathrm{dT} \% / \mathrm{dt}$ which is due only to the known applied $\mathrm{dQ} / \mathrm{dt}$.

The second relation needed in determining the $\mathrm{T}$ scale is that between $S$ and $T *$. Finding it is a little more difficult than the task just described of finding U vs. $T^{*}$. By demagnetizing adiabatically from different magnitudes of applied field $H$ at the same initial temperature $T_{i}$, different final values of $\mathrm{T}^{*}$ are obtained. Since an adiabatic process takes 
place at constant entropy, the entropy $S$ at each final $T^{*}$ with $\mathrm{H}=0$ is equal to that at the initial value of $H$ at $T_{i}$. Thus, the problem of finding $S$ vs. $T^{*}$ at $H=0$ reduces to that of finding $S$ vs. $\mathrm{H}$ at $\mathrm{T}_{i} \cdot \mathrm{A}$ number of different ways of obtaining this latter relation. will be given in the following paragraphs.

If the heat of magnetization dQ given up by the salt as it was magnetized from $\mathrm{H}=0$ isothermally at $\mathrm{T}_{i}$ were known, then the value of $S$ corresponding to the final value of $H$ would be given directly from the second law of thermodynmics;

$$
\mathrm{dS}=\frac{\mathrm{dQ}}{\mathrm{T}_{i}}
$$

However, it is experimentally impossible to measure the heat flow out of a specimen at a constant temperature, although it has been suggested that the heat of magnetization could be obtained directly by supplyzng heat to the specimen at a known rate from a heater, while at the same time demagnetizing at just the right rate to keep the temperature of the specimen constant. As far as I know, this method has never actually been used, although it is the most straightforward conceptually.

Another experimental method makes use of the Maxwell relation for magnetic materials

$$
\left(\frac{\partial \mathrm{M}}{\partial \mathrm{T}}\right)_{\mathrm{H}}=\left(\frac{\partial \mathrm{S}}{\partial \mathrm{H}}\right)_{\mathrm{T}} \text {. }
$$

By plotting a family of measured $M$ vs. $H$ curves at constant $T$ for a range of values of $\mathrm{T}$ close to $\mathrm{T}_{i}$, the quantity $(\partial \mathrm{M} / \partial \mathrm{T})_{\mathrm{H}}$ for different values of $\mathrm{H}$ at $\mathrm{T}=\mathrm{T}_{i}$ can be determined graphically, thus determining ( $\partial S / \partial H)_{T_{i}}$, which, when integrated, yields the needed $S$ vs. $H$ relation at $T_{i}$. 
Finally, a third method may be used, which is a combination of theoretical and experimental approaches. $S$ as a function of $\mathrm{H}$ and $T$ has been calculated theoretically for the perfectly paramagnetic system described earlier (15). If the salt being studied is found to obey Curie's law at and just above $T_{i}$, where thermodynamic temperatures can be measured by other means, then it may be assumed that the salt is an almost perfect paramagnetic at $T_{i}$, and the theoretical values for $S$ vs. $H$ at $T_{i}$ used. In this method, the only experimentally determined quantity needed is the Lande' or spectroscopic splitting factor $g$, which determines the value of the dipole moment per ion $\mu$ to be used.

The last method mentioned above was the one used by Daniels and Robinson (16) in the original measurements of $S$ vs. T* for CMN, using the calculated entropy values of Hull and Hull (17). Later, the same experimental data of Daniels and Robinson was reinterpreted by de Klerk (18), and new measurements on two. different samples of CMN were made by Hudson, Kaeser, and Radford (19). The curves of $S$ vs. T* obtained in these four cases differ appreciably from each other in the range below $\mathrm{T} *=0.01 \mathrm{~K}$. At about $0.006^{\circ}, \mathrm{T} *$ diverges greatly from $\mathrm{T}$, and, because of the ambiguity in the entropy measurements, the relation between $T *$ and $T$. can not be found in this range or lower. This sets the lower limit on the useful range of CMN as a thermometer. However, all investigators agree that, above $0.01^{\circ} \mathrm{K}, \mathrm{T} *=\mathrm{T}$ within the accuracy of the measurements $(20)$. This is the unique property of CMN that makes it the best available substance for magnetic thermometry. In other paramagnetic 
salts; the Curie law begins to break down a little below $l^{\circ} \mathrm{K}$. Preparation of CMN Samples for Susceptibility Measurements

Growing Crystals of CMN. The CMN crystals used in the temperature calibrations to be described later were grown from a water solution formed by mixing together solutions of cerous nitrate, $\mathrm{Ce}\left(\mathrm{NO}_{3}\right)_{3} \cdot 6 \mathrm{H}_{2} \mathrm{O}$, and magnesium nitrate, $\mathrm{Mg}\left(\mathrm{NO}_{3}\right)_{2} \cdot 6 \mathrm{H}_{2} \mathrm{O}$. It is necessary to begin with saturated solutions of these constituent compounds if the crystals are to be produced in $a$ reasonable length of time. The Handbook of Chemistry and Physics does not give a numerical value for the solubility of cerous nitrate in water, but it seems to be very large, at least twice that of magnesium nitrate which is given as 42.33 grams per 100 milliliters of water at $18^{\circ} \mathrm{C}$ (21). In fact, cerous nitrate will dissolve completely in a small amount of water, producing a solution with only about half the original volume of the salt as it came from the bottle. Saturated solutions of each constituent were made by adding enough salt so that some remained undissolved on the bottom of the containers after standing at room temperature for three days. Since the proportions by weight of the two components in CMN are about equal, and the solubility of cerous nitrate is taken to be twice that of magnesium nitrate, these solutions were mixed together in a one-to-two proportion by volume. This procedure produced a supersaturated solution of CMN which did not precipitate spontaneously, but would precipitate if stirred vigorously, or, if put into a refrigerator at about $7^{\circ} \mathrm{C}$, would form a hard solid amorphous mass of salt in a few hours, filling the entire volume occupied by the solution at room 
temperature with no uncombined water left standing above.

This supersaturated solution was diluted gradually by adding small amounts of distilled water until it would precipitate out only slowly while standing in the refrigerator in evaporating dishes. The small crystals which formed at the bottoms of the dishes were examined and some which appeared to be well formed in the characteristic hexagonal shape of CMN were removed and saved as seed crystals. The remainder were allowed to remain in the solution and were redissolved as the solution warmed to room temperature. Then, the dishes were replaced in the refrigerator and, after they had again cooled down, the seed crystals were put back in. As the crystals grew, it would be necessary every few days to remove them from solution, clean off smaller crystals which had grown in random orientations on the faces of the large crystals, and allow the solution to warm to room temperature to redissolve the precipitate along the sides and bottoms of the dishes. In this way, large crystals of up to about an inch and a half across the largest dimension were grown.

Crystaliine Form and Magnetic Anisotropy of CMN. CMN crystallizes in the trigonal system, with the cerium ions located in a simple rhombohedral lattice with one ion per unit cell of side $8.51 \mathrm{~A}$, and interaxial angle of $79.5^{\circ}$ (18). The crystals are colorless, and take the form of flat hexagonal plates. In the crystals grown as described here, the dimension across the hexagonal face was typically five times larger than the thickness, or perpendicular distance between the two large hexagonal faces. The magnetic susceptibility of CMN is very anisotropic, 
with the direction of minimum susceptibility being the axis perpendicular to the hexagonal faces. In any direction which is perpendicular to this minimum susceptibility axis, the susceptibility is a maximum, about sixty times that in the minimum direction. The measured properties cited in the preceeding paragraphs, including the inverse temperature dependence of the susceptibility, were all for the direction of maximum susceptibility. Thus, in using a sample of single crystals, it is important that the minimum susceptibility axis be nearly perpendicular to the applied magnetic field.

In the crystals described here, the chipping off of small crystallites and the removal from solution and later replacement had produced large flaws. It was felt that these would not affect the magnetic properties, because, although dislocations may have been formed where the crystal's growth was stopped and started again, it appeared that the axis of minimum susceptibility was aligned from one side of the flaw to the other.

Necessity of Ellipsoidal Shape for Susceptibility Measurements. Besides the necessary orientation of the crystal axes relative to the applied magnetic field $\mathrm{H}$ as described above, there is an additional geometrical requirement, namely, that the shape of the entire sample be that of a sphere or an ellipsoid of revolution with the axis of revolution parallel to the direction of the applied field. This latter requirement holds for the samples made of pressed or cemented CMN powder used by some experimenters, as well as for those of a few large crystals as is being described here. It is necessary in order to approximate one of the idealized conditions under which Curie's law is valid, 
that is, the assumption that the applied. field is uniform throughout the system of dipoles.

Inserting a body of uniform magnetic material of arbitrary shape into an originally uniform external magnetic field destroys the uniformity of the fièld. The boundary value problem (in terms of the magnetic field vectors) which is thus created is, in general, insoluble analytically. However, it is certain that the internal field is not uniform, but varies from point to point. Only in the case of the ellipsoid or sphere is the field inside the body, ${ }_{-}$int uniform (22). In this case, $\mathrm{H}_{\text {int }}$ has the same direction as the original external field $H$, and a magnitude. given by

$$
\mathrm{H}_{\text {int }}=\mathrm{H}-\mathrm{PM}=\mathrm{H} /(\mathrm{I}+\mathrm{PX}) \text {. }
$$

The value of the dimensionless constant $\mathrm{P}$, known as the demagnetizing factor, depends only on the eccentricity of the ellipsoid. For a sphere, $P=1 / 3$. The external field is changed from a uniform one to that of a point dipole at the center of the elifipsoid with its axis in the direction of the original field.

The CMN sample used in the temperature calibration apparatus of Fig. I consisted of two hemispheres, each made from a single crystal, cemented to either side of a support made of thin copper sheet. The large hexagonal face of the crystal is used as the base of the hemisphere, so that, when the crystals are attached with this surface in a vertical plane, as in Fig. 1, the correct orientation with respect to the applied magnetic field is obtained.

It was found to be impossible to cut the CMN with any 


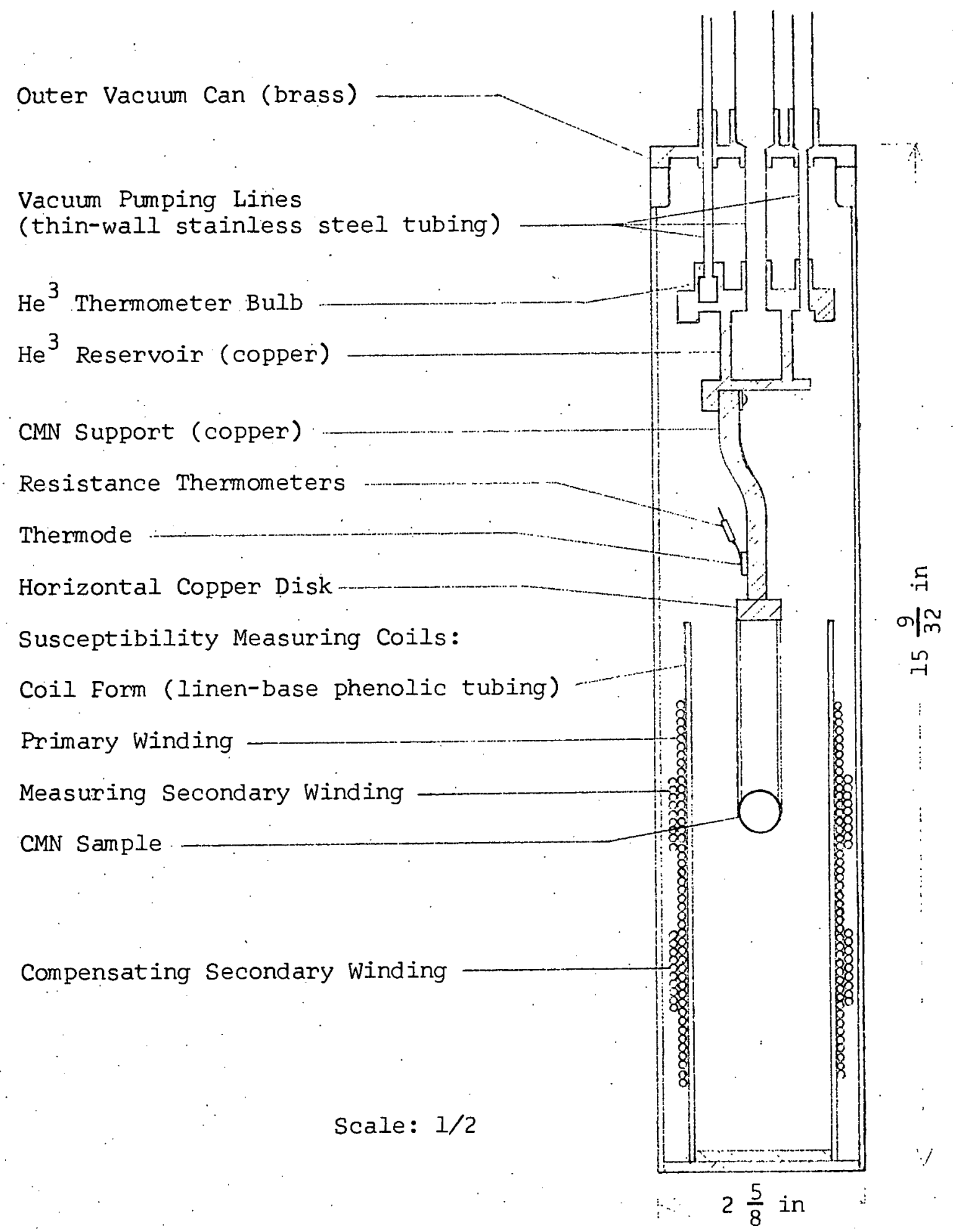

Fig. I Cross Sectional View of Cryostat Containing Apparatus for Magnetic' Susceptibility Measurements 
sharp tool because of the tendency of the material to chip. Each crystal was first cut to a very rough cylinder with a fine jeweler's saw, then finished by rubbing by hand with no. 120 sandpaper to form a hemisphere.

Apparatus for Calibration of Resistance Thermometers

Description of Cryostat. A cross-sectional view of the entire cryostat as arranged for the calibration of resistance thermometers against the magnetically determined temperature is shown in Fig. 1. Temperatures as low as about $0.3^{\circ} \mathrm{K}$ can be achieved in this cryostat by the following procedure: First, the cryostat is immersed in Iiquid helium $\left(\mathrm{He}^{4}\right)$, with the vacuum can filled with about 5 torr. of helium gas to bring the inner part into equilibrium with the liquid helium bath. Then, the vapor pressure of the He ${ }^{4}$ is reduced by pumping to bring the temperature of the bath below $2^{\circ} \mathrm{k}$, and $\mathrm{He}^{3}$ gas is admitted to the $\mathrm{He}^{3}$ reservoir and thermometer bulb lines. When an amount of liquid $\mathrm{He}^{3}$ has condensed in both the reservoir and thermometer bulb, the outer vacuum can is evacuated to below $10^{-4}$ torr., thermally isolating it from the $\mathrm{He}^{4}$ bath except for the small heat leak through the thin stainless steel tubes and the electrical lead wires to the resistance thermometers, and a small amount of heating by radiation. A closed cycle pumping system is then used to pump on the vapor of the $\mathrm{He}^{3}$ in the reservoir, reducing its vapor pressure and temperature, while the vapor pressure in the thermometer bulb line is monitored to give the $\mathrm{He}^{3}$ vapor pressure temperature. The bulb line is not being pumped upon, and thus, does not have a pressure 
gradient, except for that caused by the thermomolecular pressure ratio, as described in section $I$ of this thesis.

Thermal conductivity measurements on various irradiated $\mathrm{KCl}$ crystals had been made in this same cryostat with the susceptibility apparatus omitted. The clamp on the $\mathrm{He}^{3}$ reservoir shown in Fig. I holding the copper support for the CMN was used in the conductivity experiments to hold the cold end of the thermal conductivity sample (23). These crystal samples were about 2 inches long, and rectangular in cross section. A small heating coil was clamped to the sample's lower end for the heat source, and two indium-faced clamps or "thermodes" with resistance thermometers attached were spaced a measured distance apart on the sample to measure the temperature gradient. In the course of the thermal conductivity experiments, these resistors had been calibrated against the vapor pressure temperature scales of $\mathrm{He}^{4}$ and $\mathrm{He}^{3}$ in their respective ranges. Since the $\mathrm{He}^{3}$ vapor pressure scale is unreliable below about $0.6^{\circ} \mathrm{K}$ because of the large uncertainties in the thermomolecular pressure correction, it was desired to use the magnetic susceptibility thermometer to extend the calibration of the resistors down to the lowest temperatures which could be achieved by the cryostat.

Susceptibility Measuring Coils. The coils shown in Fig. 1 are of a design described by Abel, Anderson, and Wheatley (24). They are in the form of a mutual inductance, with a relatively long ( 5 inches) solenoidal primary to give an approximately uniform field at the location of the CMN sample, and two sec- 
ondaries, each one inch in length, wound in opposite directions on the outside of the primary and spaced one inch apart. The salt sphere is placed at the center of the upper secondary. The lower, opposing secondary is connected in series to cancel the voltage which would be induced in the upper secondary with no magnetic material inside the coils, so that only the change in mutual inductance caused by the salt's presence is measured. This is important because the mutual inductance between the primary and one secondary is typically of the order of 100 millihenries in vacuun, while the increase in this mutual inductance due to the presence of the CMN is only around 100 microhenries, or a thousand times smaller (24).

The primary winding of 1500 turns, and the secondaries of 1000 turns each were wound of \#30 AWG copper wire on an 1 13/16 inch O.D., 1/16 inch thick cylinder of linen-base phenolic. This material was used for the coil form because it is both electrically non-conducting and non-magnetic, and thus, will not mask the small magnetic effect of the CMN. The coil form is centered at the bottom of the outer vacuum can and is put in thermal contact with it by the use of a thin film of heat conductive vacuum grease between the bottom of the coil form and the inner bottom of the vacuum can. Thus, the liquid $\mathrm{He}^{4}$ bath can act as a heat sink for any Joule heat generated in the primary winding.

Mounting of CMN Sample. As shown in Fig. 1, the upper part of the support for the CMN sample is a $1 / 4$ inch square. copper bar, the top of which is clamped to the $\mathrm{He}^{3}$ reservoir. 
The thermode from the thermal conductivity experiments with the resistance thermometers to be calibrated is also attached to this part of the support. At the lower end of this $1 / 4$ inch square section is a horizontal copper disk of $1 / 2$ inch diameter, the bottom of which is tinned with solder. The lowest part of the support is made from 0.025 inch thick copper sheet. It is cut to the form of a $1 / 2$ inch diameter circle (to which are cemented the two hemispheres of (MN), plus two straight vertical parts, each bent into an L-shaped cross-section of dimensions $0.030 \mathrm{in}$. $X 0.030 \mathrm{in}$. (which connect the CMN sphere to the upper part of the support). The CMN is cemented to the copper sheet with General Electric no. 7031 varnish, which is also used to coat the exposed surfaces of the spherical sample.

It is necessary for the CMN sample to come quickly to equilibrium with the resistance thermometers and the $\mathrm{He}^{3}$ reservoir, since, in the calibration, it is assumed that these three points are all at the same temperature. Copper was used as the material for the support, since it is a good heat conductor. Thermal contact resistance was minimized by using thermally conductive vacuum grease between contacting surfaces wherever parts of the supporting structure were fastened together by clamps or screws. Since single crystal salts are; in general, good heat conductors, the copper sheet sandwiched between the two single crystal hemispheres provided a good thermal contact to the entire CMN sample.

There is a possibility that the eddy currents induced in the copper support by the alternating current in the measuring 
coil primary may cause enough heating to raise the temperature at the location of the CMN above that at the $\mathrm{He}^{3}$ reservoir. However, the upper portion of the support including the horizontal copper disk is an inch or more above the end of the primary winding, and thus, not in the region of highest magnetic field. In addition, the tin-lead alloy solder which covers the bottom of this horizontal disk is a superconductor in the temperature range of the experiment, and the diamagnetic property of this superconducting layer will prevent the magnetic flux from penetrating this surface:

The lower part of the support, that made of the 0.025 in. thick sheet stock, must necessarily be in the magnetic field, so, a calculation was made to determine the effect of eddy current heating in this part. Considering only circular current paths, with the maximum diameter path determined by the thickness of the material, the heating in this entire part is $1.3 \times 10^{-7}$ watt for the primary current used in the experiment, $9.2 \times 10^{-4}$ amperes r.m.s. at $204 \mathrm{~Hz}$. Taking this amount of heat to be generated at the location of the CMN sphere and conducted away by the two narrow upright sections of this part, the rise in temperature at the CMN would be $3.0 \times 10^{-5}$ degree $\mathrm{K}$ above that of the $\mathrm{He}^{3}$ reservoir at $0.3^{\circ} \mathrm{K}$. The thermal conductivity of copper was taken to be $1.2 \mathrm{watt} / \mathrm{cm} . \rho_{\mathrm{K}}$ at $0.3^{\circ} \mathrm{K}$ (25). The conditions at $0.3^{\circ} \mathrm{K}$ represent the worst case for this eddy current calculation, for, the thermal conductivity of copper increases at higher temperatures (25), while its electrical resistivity remains approximately constant at $4.65 \times 10^{-10} \mathrm{ohm} \cdot \mathrm{cm}$ 
up to $4^{\circ} \mathrm{K}(26)$.

Mutual Inductance Bridge

Bridge Circuit. The circuit used for the susceptibility measurements (Fig. 2) is essentially that described by Maxwell (27), and is a modification of the "Hartshorn bridge". The basic Hartshorn bridge directly measures an unknown mutual inductance by putting it in series with a calibrated variable mutual inductor connected with secondaries opposing. The adjustable inductor is varied until the total voltage across both secondaries becomes zero. The circuit of Fig. 2 achieves the quivalent of a decade variable mutual inductance by the use of a Gertsch model 1011 ratio transformer, which is a seven-decade autotransformer intended for use as a precision A.C. voltage divider. This ratio transformer taps off any desired fraction of the secondary voltage of a 50 millihenry fixed mutual inductance, and adds it, in opposite sense, to the voltage induced in the measuring coil secondary. The potentiometer $\mathrm{R}$ and the DPDT switch are used to introduce a voltage into the secondary circuit which is either in phase or $180^{\circ}$ out of phase with the primary current in order to balance out the "resistive" component of the secondary voltage of the cryostat coils.

Lock-In Amplifier. A Princeton Applied Research model HR-8 lock-in amplifier serves both functions of oscillator and null-indicating detector in the circuit of Fig. 2. This instrument uses electronic switching circuits to chop an incoming low level A.C. signal at twice a set reference frequency, and invert the signal for every other half-cycie of the reference 


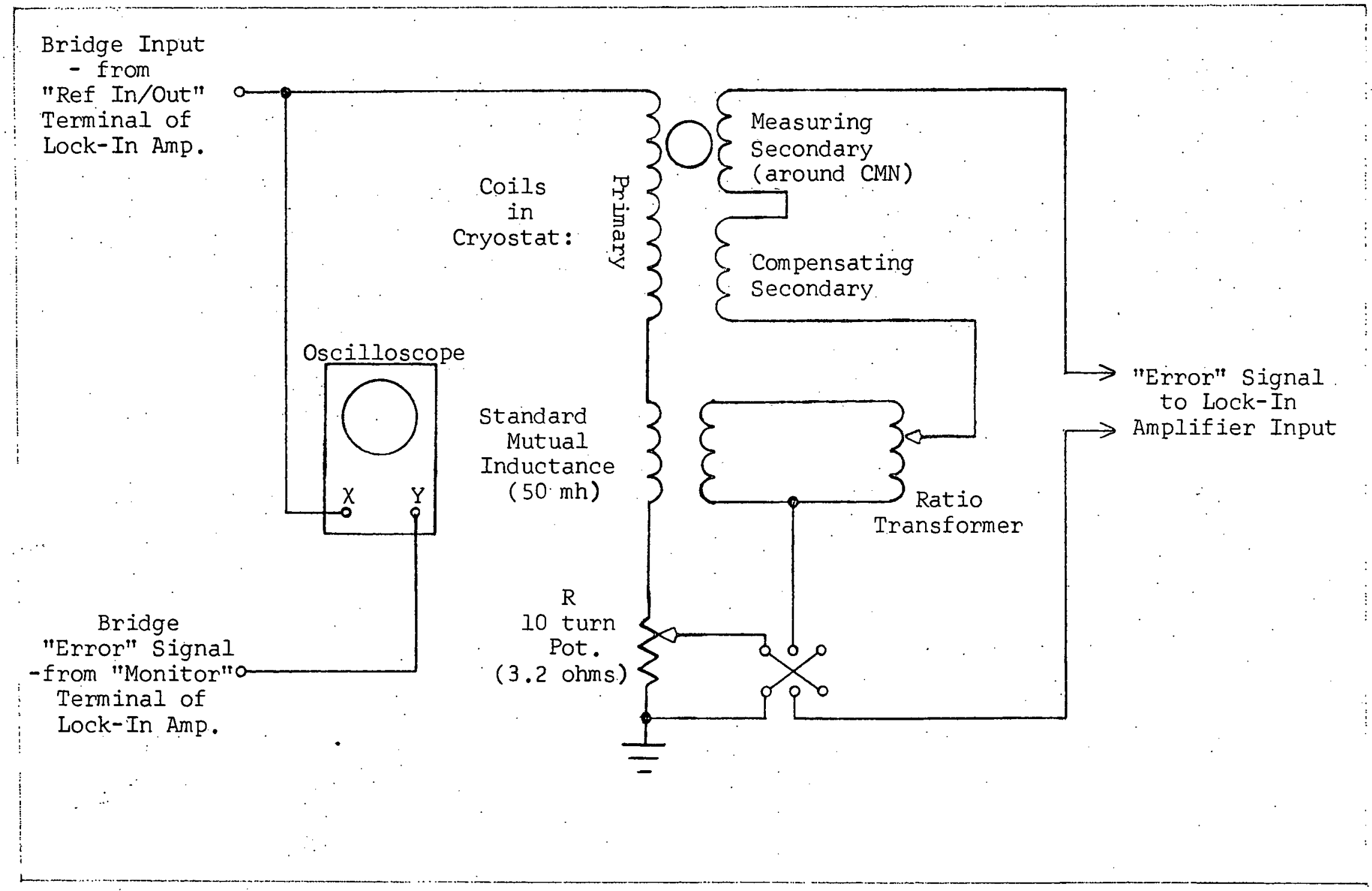

Fig. 2 Mutual Inductance Bridge Circuit 
frequency. This process has the effect of full-wave rectifying the Fourier component of the signal which has the same frequency as the reference, and causing the time average of the components at all other frequencies to be zero. This chopped and inverted signal is then applied to a D. C. galvanometer, which thus indicates the effective value of the signal component at the reference frequency. For this lock-in detection process to work, it is necessary that the reference voltage and the signal component at that frequency are in phase with each other. This is accomplished by adjusting a manual control which shifts the phase of the reference signal until the maximum meter deflection is obtained. The output of the internal oscillator which supplies the reference signal is also taken (before going through the phase shifter) to supply the primary current in the inductance bridge.

Oscilloscope. A Tektronix RM503 oscilloscope is also used to. monitor the signal from the bridge. It is used in the "external sweep" mode of operation, with the "Ref. In/Out" terminal of the HR-8, which is the bridge input, connected to the oscilloscope's horizontal input, and the "Monitor" terminal of the HR-8 connected to the vertical input. If the "Meter/Monitor" switch on the lockin amplifier is set to the "Signal" position, the vertical deflection of the oscilloscope trace is driven by the actual output or error signal from the bridge. The usual Lissajous pattern produced by two signals of the same frequency is obtained, so the trace can be readily used as both a phase indicator and approximate null indicator. However, the meter of the HR-8 is not connected to the lock-in detector at this switch setting. 
In order to use the $H R-8$ as a lock-in detector, the "Meter/ Monitor" switch must be turned to the "out" position, which, besides connecting the panel meter, also applies the chopped and inverted detector circuit output to the vertical input of the oscilloscope. The trace is no longer a simple Lissajous figure, but a closed curve with cusps if the reference and error signals are in phase. If these signals are out of phase, the trace will open, with vertical gaps indicating that the chopping is taking place at a point of the waveform other than at the node every half cycle. Thus, the oscilloscope may still be used as an approximate phase difference monitor.

Operating Procedure. The first step in making a series of susceptibility measurements with this circuit is to set the operating frequency of the lock-in amplifier. The choice of frequency is critical in obtaining the maximum sensitivity from the bridge.

A noise effect is observed at the higher sensitivity settings of the HR-8 which is apparently due to a beat between the error signal from the bridge and noise pickup from the $60 \mathrm{~Hz} \mathrm{A.C:} \mathrm{power}$ lines. This effect appears as a regular periodic osciliation of the oscilloscope trace in the vertical direction. At most error signal frequencies around $100 \mathrm{~Hz}$, this beat frequency is low enough for these oscillations to be readily seen and counted on the oscilloscope screen, but high enough so that the D.C. meter on the lock-in amplifier undergoes only a rapid small oscillation about an easily determined center position. If the frequency control of the HR-8 is brought close to a multiple or sub-multiple of 60 , e.g., 20, 30, 60, or $120 \mathrm{~Hz}$, the oscillations are observed 
to slow down to a few sycles per minute, causing very large slow excursions of the meter needle, making it impossible to read the meter.

Once the operating frequency has been set to minimize the above beat effect, it must remain fixed for the entire experiment. Even a small change in frequency will change the indicated mutual inductance by an amount large compared to the variation with temperature which is to be measured.

In making the first mutual inductarice measurement of a series, an approximate null is first found with the sensitivity control of the HR-8 set to about the $20 \mathrm{mv}$. range, and the "Meter/Monitor" switch set to "Signal", so that the oscilloscope is used as the null detector. The horizontal and vertical amplifiers of the oscilloscope are set to obtain an elliptical pattern. The potentiometer $R$ is then adjusted to bring the axis of this elliptical trace to a horizontal position, and the ratio transformer setting is changed until the trace closes into a horizontal line.

After this initial adjustment at low sensitivity, the "Meter/Monitor" switch is set to "out", and higher sensitivity settings are used to find the final setting of the ratio transformer. The potentiometer $R$ is not readjusted at the higher sensitivity, however. The value used in the present circuit ( 3.2 ohms) is apparently large enough to make this adjustment somewhat over sensitive, so $\mathrm{R}$ is left at the setting determined initially for the entire series of mutual inductance measurements. This means that the resistive component of the secondary voltage 
is never completely cancelled out, so that a minimum error signal is found by adjusting the ratio transformer, rather than a complete nuil. Usually, the minimum error signal will be small enough so that it will be found with the sensitivity turned up all the way to the 50 or $20 \mathrm{uv}$. range. (The $20 \mathrm{uv}$. setting of the sensitivity dial actually means that a signal input of $200 \mathrm{nv}$. ( $2 \times 10^{-7}$ volt) is sufficient to cause a full scale deflection of the meter. The numbers marked on the sensitivity control settings do not include a 100:1 voltage amplification in the preamplifier.)

Also, again because the resistive component of secondary voltage is not completely balanced out, the phase difference between the error signal and the reference signal will vary with ratio transformer settings. This effect becomes relatively large when near the minimum error signal, so that it is necessary to readjust the phase control after each change in ratio transformer setting in order to decide which ratio transformer setting actually results in the smallest error signal.

For subsequent susceptibility measurements at different temperatures, only the part of the procedure at high sensitivity is repeated, since the change with temperature is small compared to the total mutual inductance.

Results

Fig. 3 shows some results of the first completed calibration run with the apparatus of Fig. 1. This run had been pre-. ceeded by several unsuccessful attempts, most of which had failed because the wire of either the primary or secondary winding of the 


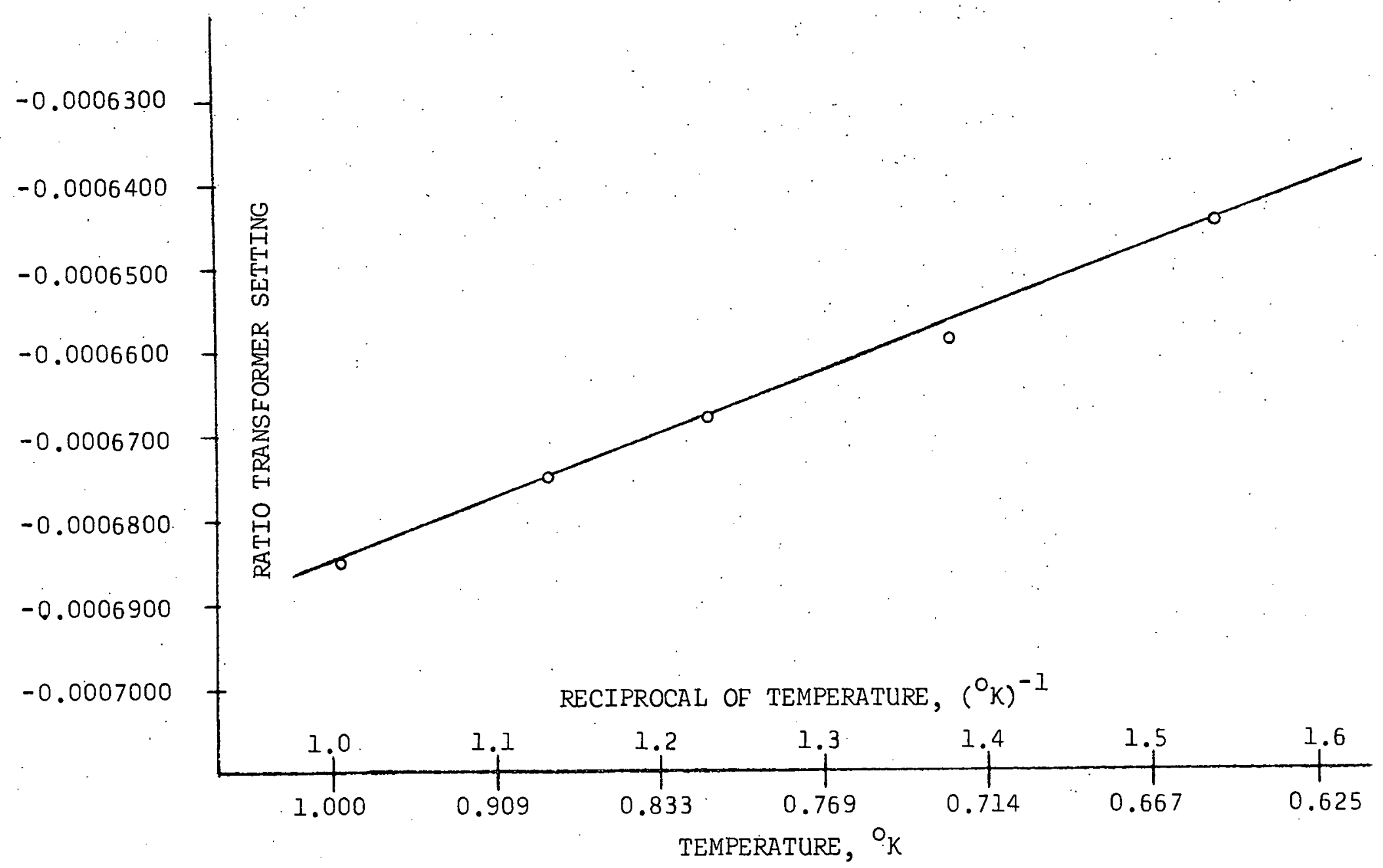

Fig. 3 Calibration Points: Mutual Inductance vs. $\mathrm{He}^{3}$ Vapor Pressure Temperature 
measuring coil broke at liquid helium temperature. This original, troublesome coil was of the same design and construction as the one which has been described, except for the use of \#34 AWG wire in the primary winding and \#36 AWG in the secondary. It was repaired several times, only to break again in a different location in the next run. Perhaps the entire lot of wire from which it was wound was improperly annealed, or for some other reason was excessively brittle. This entire coil was finally discarded, and the coil using 30 AWG wire (from a different source) in both windings was made. The latter coil showed no such tendency to become open-circuited at low temperature.

The data points in Fig. 3 represent calibration points in which the measured mutual inductance is plotted against the inverse of the $\mathrm{He}^{3}$ vapor pressure temperature. The vapor pressure of $\mathrm{He}^{3}$ in the thermometer bulb line (Fig. 1) was measured with a Granville-Phillips Capacitance Manometer in this experiment. The calibration is done from $1^{\circ} \mathrm{K}$ to $0.65^{\circ} \mathrm{K}$. Below $0.65^{\circ} \mathrm{K}$ the extrapolation of the inductance vs. 1/T graph so obtained is taken to be the more accurate temperature scale, and was used to recalibrate the resistance thermometer.

The numbers plotted as $M$ along the vertical axis are the indicated settings of the ratio transformer at null. (The actual value of mutual inductance is given by multiplying this number by 50 millihenries.) The negative values of this number in Fig. 3 indicate that, for this particular set of coils, CMN sphere, and surroundings, the inductance of the lower or compensating coil is sightly greater than that of the upper coil 
surrounding the CMN Sample, so the ratio transformer must add a voltage in phase with that induced in the upper secondary rather than out of phase - in order to achieve a null.

At the lowest temperature attained by the cryostat, i.e., with the maximum pumping rate being used on the liquid $\mathrm{He}^{3}$ in the reșervoir, the inductance bridge balanced at a ratio transformer setting of -0.000517 . By extrapolating the lower temperature part of Fig. 3, the value of $T$ corresponding to this value of $\mathrm{M}$ is found to be $0.304^{\circ} \mathrm{K}$. The resistance thermometer under these conditions was measured to be $59 \mathrm{~K} \Omega$, and the temperature estimated on the basis of the $\mathrm{He}^{3}$ vapor pressure measurement about $0.38^{\circ} \mathrm{K}$. The magnetically determined temperature is more consistent with the expectation of the lowest attainable temperature of the cryostat. 
III. RESISTANCE. THERMOMETRY AT LIQUID HELIUM TEMPERATURES

Characteristics of Low Temperature Resistance Thermometers

Usefulness of Resistance Thermometers in Thermal Conductivity

Experiments. As previously mentioned, the temperature dependence of electrical resistivities of platinum and other metals are not useful for thermometric purposes in the range of liquid helium temperatures. However, it has been found that ordinary carbon composition resistors and resistance elements of semiconductor materials are sensitive indicators of temperature in this range.

The secondary thermometers used most widely in the thermal conductivity experiments at the IIT Low Temperature Laboratory have been $1 / 10$ watt Ohmite carbon composition resistors. These units have a number of advantages for this application. They are inexpensive and readily available. They come in a wide variety of nominal room-temperature resistance values, so that a suitable nominal value may be chosen to give the optimum sensitivity in the intended temperature range of the experiment. Finally, they are very small in physical size, with a correspondingly small heat capacity. As such, they can be placed in thermal contact with a local area of a crystal specimen without significantly affecting the overall temperature profile of the specimen. Germanium resistance thermometers manufactured by Texas Instruments, Inc. have also been used in some of the experiments. Carbon Composition Resistors as Thermometers. Because of the great convenience in the use of this type of thermometer, a number of experimenters have studied the temperature dependence 
of the resistance of carbon composition resistors (28).

There is no known physical relation between the resistance and the thermodynamic temperature which can be deduced from fundamental principles (analogous to the susceptibility - temperature relationship of paramagnetic salts). There is not even an agreed upon empirical formula by which the resistance thermometers may be calibrated on the bais of measurements at a few known temperature points, is the case for platinum resistance thermometers.

Perhaps the closest approach to such a formula has been made by Clement, Dolecek, and Logan (29), who noted that curves of log $R$ vs. $\log \mathrm{T}$ for all nominal values of Allen-Bradley resistors the Ohmite resistors we use are actually manufactured by AllenBradley - could be superimposed by a translation of axes. They have tabulated a universal calibration curve for these resistors which requires that only two scaling parameters need be found for a particular resistor by calibrations at two temperatures. They report that all resistance-temperature data which they had on $1 / 10, I / 2$, and $I$ watt Allen-Bradley resistors $f i t$ this function within 1 to 2 percent.

Some reported disadvantages in using carbon composition thermometers have been a lack of reproducibility of temperature calibration after temperature cycling between liquid helium temperature and room temperature (particularly if the resistor had been exposed to gaseous or liquid helium) and a long-term aging effect on the temperature calibration. The magnitude of this lack of reproducibility should be noted, however. In tests conducted by Edlow and Plumb (30) at the National Bureau 
of Standards on $1 / 2$ watt Allen-Bradley resistors, temperature cycling between immersion in liquid helium and exposure to room temperature in a helium atmosphere shifted the $R$ vs. $T$ calibrations of these resistors by about a millidegree $k$. In these same tests, 4 weeks of continuous immersion of the resistors in liquid helium at constant temperature produced a change in resistance equivalent to that which would be caused by a temperature change of about 3 millidegrees.

In order to avoid any ambiguity in the resistance thermometer calibration, all the carbon composition resistors used in the thermal conductivity experiments at the IIT Low Temperature Laboratory were calibrated against the heliun vapor pressure temperature at many points during each experimental run.

Germanium Resistance Thermometers. To overcome some of the difficulties encountered with the use of carbon composition resistance thermometers, and approach the precision and reproducibility achieved by platinum units at higher temperatures, various manufacturers have developed semiconductor resistance thermometers. One such unit, which has been used at the IIT Low Temperature Laboratory is a gallium-doped germanium resistor with which the manufacturer, Texas Instruments, Inc., has supplied complete calibration curves from $1.5^{\circ}$ to $40^{\circ} \mathrm{K}$. The stated accuracy is $\pm 0.3 \%$ or better, and the reproducibility under repeated temperature cycling is within $\pm 0.05 \%$. A practical advantage of this unit is that it provides a thermometer that is independent of the vapor pressure temperature measurement. Thus, a comparison of the temperatures indicated by these two means can be used 
to check, for instance, the thermal contact between the helium bath and the interior of the cryostat, or to check for heat leaks in the apparatus.

\section{Resistance Measuring Circuits}

A.C. Wheatstone Bridge. The circuit most frequently used in measuring the resistance of the resistance thermometers is shown in Fig. 4. This is the familiar wheatstone bridge in which the value of an unknown resistance is found by adjusting the variable resistor until the current through the detector becomes zero. This means that the ratio of the resistance of the variable resistor to the unknown is the same as the ratio of the two fixed resistors in the other two "arms" of the bridge. If these two fixed resistors are the same, as is the case in Fig. 4, in which they are each $10 \mathrm{k} \Omega$, then the resistance of the unknown is equal to the setting of the variable resistor.

The switching arrangement used in the bridge of Fig. 4 enables the total resistance of any one of several unknown resistors to be measured, as well as the difference in resistance between any two of them. These unknowns are, of course, the resistance thermometers in the cryostat. These have numbered as many as seven, with three on each thermode on the sample, and one affixed directly to the $\mathrm{He}^{3}$ reservoir can. If the switch marked $\mathrm{T}-\Delta \mathrm{T}$ in Fig. 4 is closed, (i.e., in the position marked T), the setting of the decade resistors at null indicates the total resistance of the resistor selected by the multi-position switch $R$. If switch $\mathrm{T}-\Delta \mathrm{T}$ is open, then the setting of the decades at null gives the difference in resistance between the resistor selected 


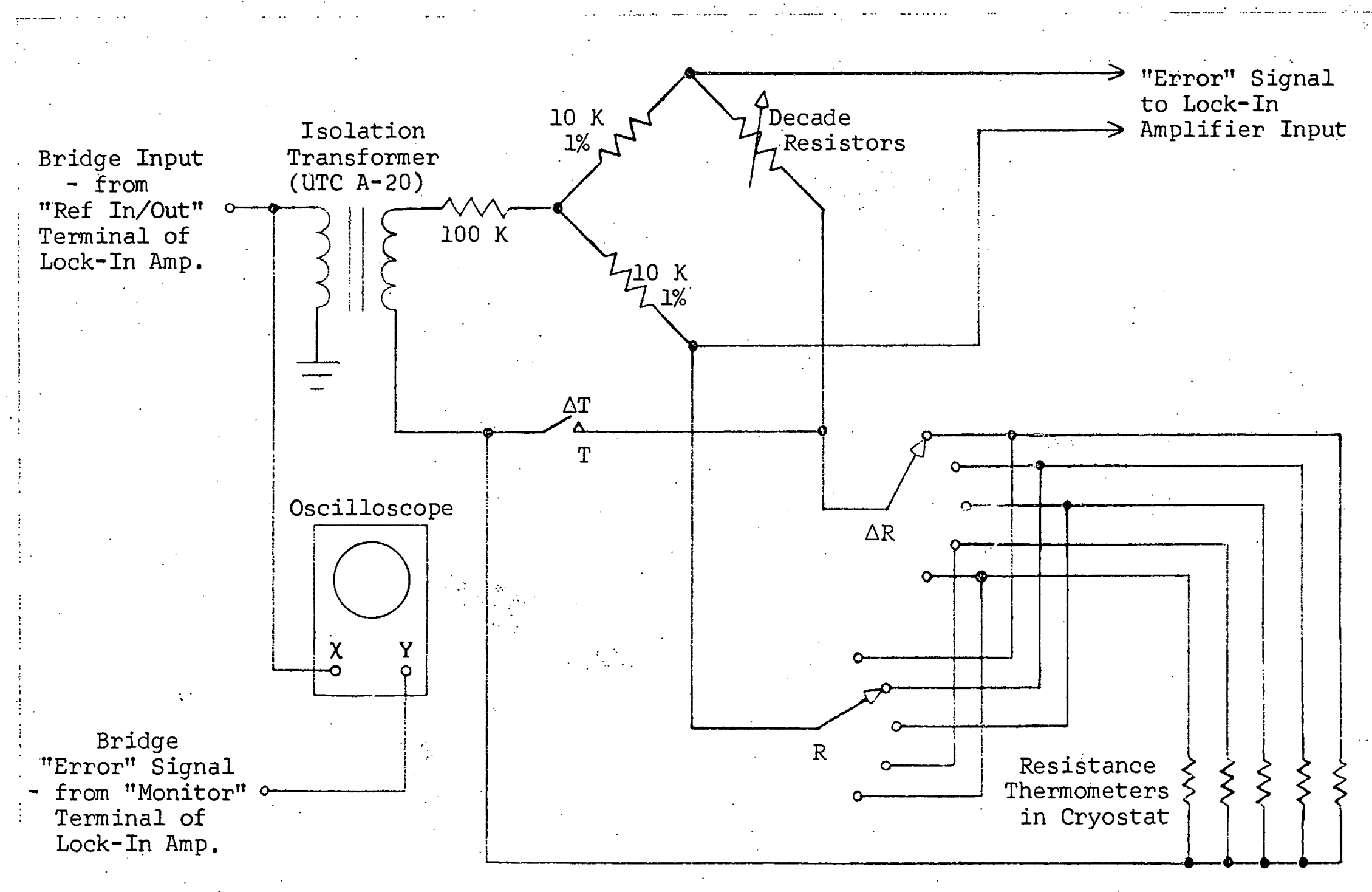

Fig. 4 A. C. Wheatstone Bridge Circuit 
by switch $R$ and that selected by switch $\triangle R$. In order to be able to balance the bridge in this latter case, the resistor selected by $\dot{R}$ must be the larger of the two. No balance can be obtained in either case if both switches $R$ and $\Delta R$ are turned to the same resistor, since in that case, the entire unknown arm of the bridge is shorted out by the switch contacts.

Use of Lock-In Amplifier with Wheatstone Bridge. The bridge is of the A.C. type and uses the HR-8 lock-in amplifier described previously as oscillator and detector, or alternately, a Princton Applied Research model, JB-4 lock-in amplịfier and CR4-A preamplifier. In order to minimize capacitive and inductive effects and to utilize the narrowest pass band of the adjustable filters of the CR4-A, if it is used, a frequency as low as possible is used. Most often, this has been around $22 \mathrm{~Hz}$. Again, as with the inductance bridge, multiples and sub-multiples of $60 \mathrm{~Hz}$ must be avoided.

The procedure for using the lock-in amplifier in this circuit is somewhat simpler than that for the mutual inductance bridge. First of all, there is only one kind of circuit element, the decade resistors, to be adjusted to obtain a null. Secondly, the phase difference between reference and error signals is much less critical in this case. It is sufficient to set the phase shift control for maximum meter deflection just once during a series of measurements. The phase is adjusted when the bridge is considerably unbalanced, then the decades are adjusted to make the meter reading go to zero, with the sensitivity of the lock-in amplifier turned up as needed. It may be seen by the oscilloscope 
trace that the change in relative phase in the final approach to null is small, and it has been found that consistent and repeatable measurements can be made without any further phase adjustment.

Potentiometer Method. The Wheatstone bridge is not useful for measurements on resistance thermometers whose resistance is below a few hundred ohms. A large uncertainty in the measurements on low value resistors comes from the lead wires to the cryostat, which have a resistance of approximately 80 ohms. Their resistance is also temperature dependent, and different parts of the wires are at different temperatures all the way from room temperature to that of liquid helium, so that an accurate correction factor can not be determined. However, in some instances, it is necessary to use resistance thermometers in their low resistance range. For example, it is possible to operate the cryostat of Fig. I at temperatures above the normal boiling point of $\mathrm{He}^{4}$ by applying power to a heating coil wound around the (empty.) $\mathrm{He}^{3}$ reservoir. In this mode of operation, the $\mathrm{He}^{4}$ vapor pressure temperature scale can no longer be used, and the only temperature standard available in our laboratory is the calibrated germanium resistance thermometer, whose resistance goes from 1000 ohms at $5^{\circ} \mathrm{K}$ to 6 ohms at $40^{\circ} \mathrm{K}$. To measure these low resistances, a potentiometer method is used. A direct current is applied to the resistor to be measured, and the voltage drop caused by this current across the resistor is measured through a second pair of lead wires with a Leeds and Northrup type $k-3$ potentiometer. The potentiometer is then switched to measure the voltage drop across a known 
standard resistor in series with the unknown resistance and the current source. This gives a measure of the current through the unknown, and its resistance is then calculated from $\mathrm{Ohm}^{\text {'s }} \mathrm{Law}$. Some Results Using Carbon Composition Resistance Thermometers

Experimental Procedure. The resistance vs. temperature calibrations of carbon composition resistors to be described in the next few paragraphs were obtained as part of a series of experiments to-measure the effect of defect centers induced by gamma-irradiation on the thermal conductivity of single crystals of $\mathrm{KCl}$ (23). In such measurements, it is necessary to know the temperature at two points along the crystal sample, or, rather, the difference in temperature between the two points and the absolute temperature at one of them. Two resistors are chosen which are matched as closely as possible in resistance both at room temperature and at the temperature of liquid nitrogen $\left(77.3^{\circ} \mathrm{K}\right)$. One of these resistors is attached to each of the two thermodes by soldering one of its leads directly to the thermode for a good thermal contact. For calibration, the difference in resistance between these two resistors, and the total resistance of the one on the upper thermode are measured using the wheatstone bridge while the entire sample is at the temperature of either the $\mathrm{He}^{4}$ bath or the $\mathrm{He}^{3}$ bath. Then, when heat is applied at the bottom of the sample, these quantities are again measured, and the temperature of the upper thermode and the difference in temperature between the thermodes is inferred from the calibration data.

Explanation of Resistance vs. Temperature Curves. In the 
experiments described here, two pairs of matched carbon composition. resistors were used to cover the temperature range over which measurements were made. Figs. 5 and 6 represent the calibrations of the resistors from each pair which were mounted on the upper thermode: In Fig. 5, a resistor with a nominal room temperature resistance of 12 ohms covers the resistance range of $1 \mathrm{k} \Omega$ to $50 \mathrm{k} \Omega$ - the optimum range for the wheatstone bridge - for a temperature range of about $1.0^{\circ} \mathrm{K}$ to $0.4^{\circ} \mathrm{K}$; and in Fig. 6 , a nominal $68 \mathrm{ohm}$ resistor covers this same resistance range for the temperature range of $4.0^{\circ} \mathrm{K}$ to $1.0^{\circ} \mathrm{K}$. In Fig. 5, the temperature was determined by the $\mathrm{He}^{3}$ vapor pressure measured with a GranvillePhillips capacitance manometer. In Fig. 6, the temperature scale was determined from the $\mathrm{He}^{4}$ vapor pressure measured by a Wallace and Tiernan aneroid manometer and a Stockes McLeod gauge.

The calibration points on these resistance vs. temperature curves are designated by run numbers 8 through 11 . These numbers were used to identify the data taken during different experimental runs of low temperature thermal conductivity measurements. Between runs 8 and 9 , the entire cryostat, including the $\mathrm{KCl}$ sample and both resistors of Figs. 5 and 6 were kept at liquid nitrogen temperature and irradiated for 93 hours by a co ${ }^{60}$ gamma ray source at a dose rate of $1.6 \times 10^{5}$ roentgens/hour. This irradiation did not show any effect on the resistance. vs. temperature calibration. Neither did temperature cycling or aging appear to have any effect. Between runs 9 and 10 , and 10 and 11 , the resistors were kept at room temperature. The total time elapsed between runs 8 and 11 was about six weeks. 


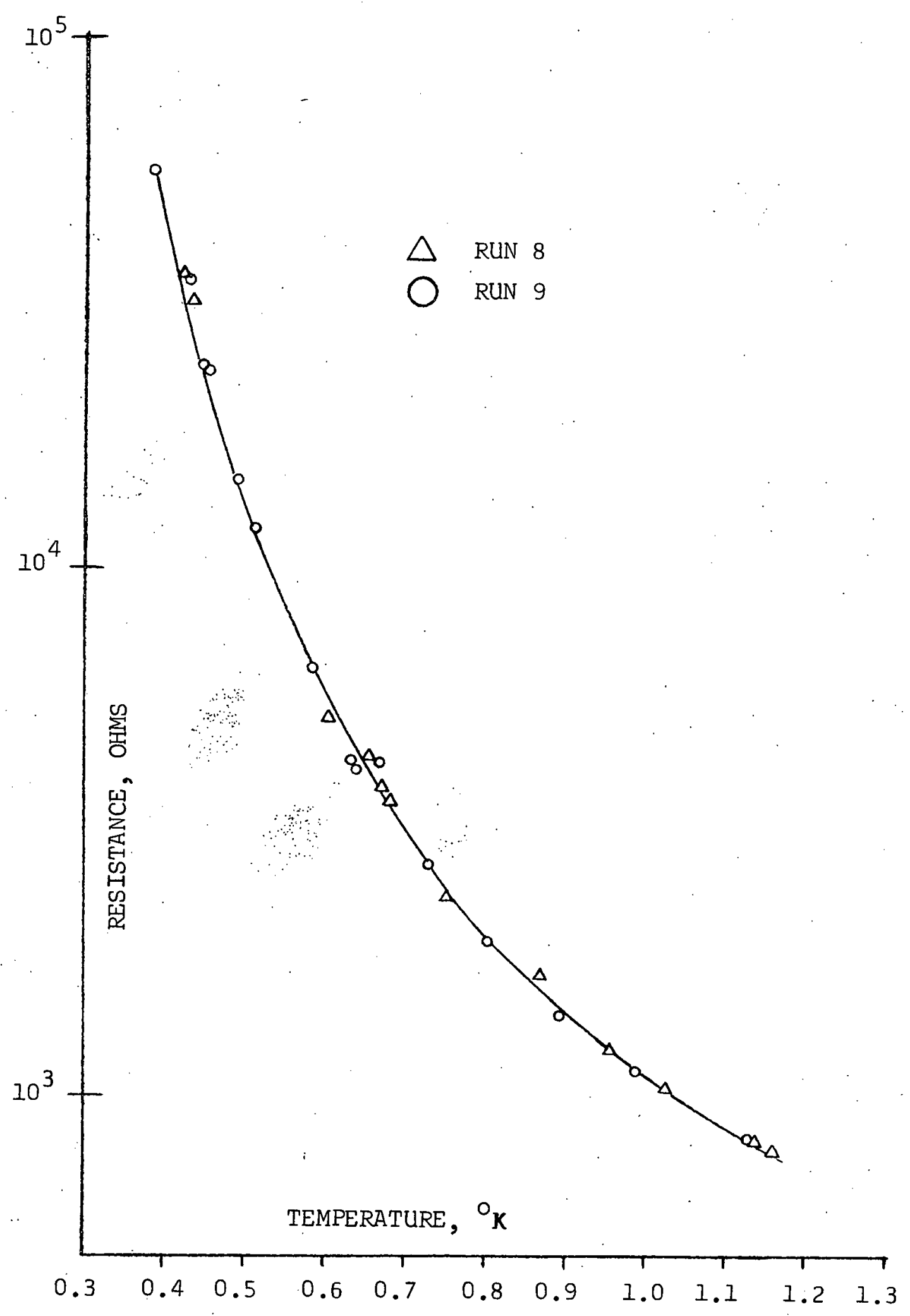

Fig. 5. Resistance vs. Temperature Calibration Curve for 1/10 Watt Carbon Composition Resistor, 12 Ohms Nominal Resistance 


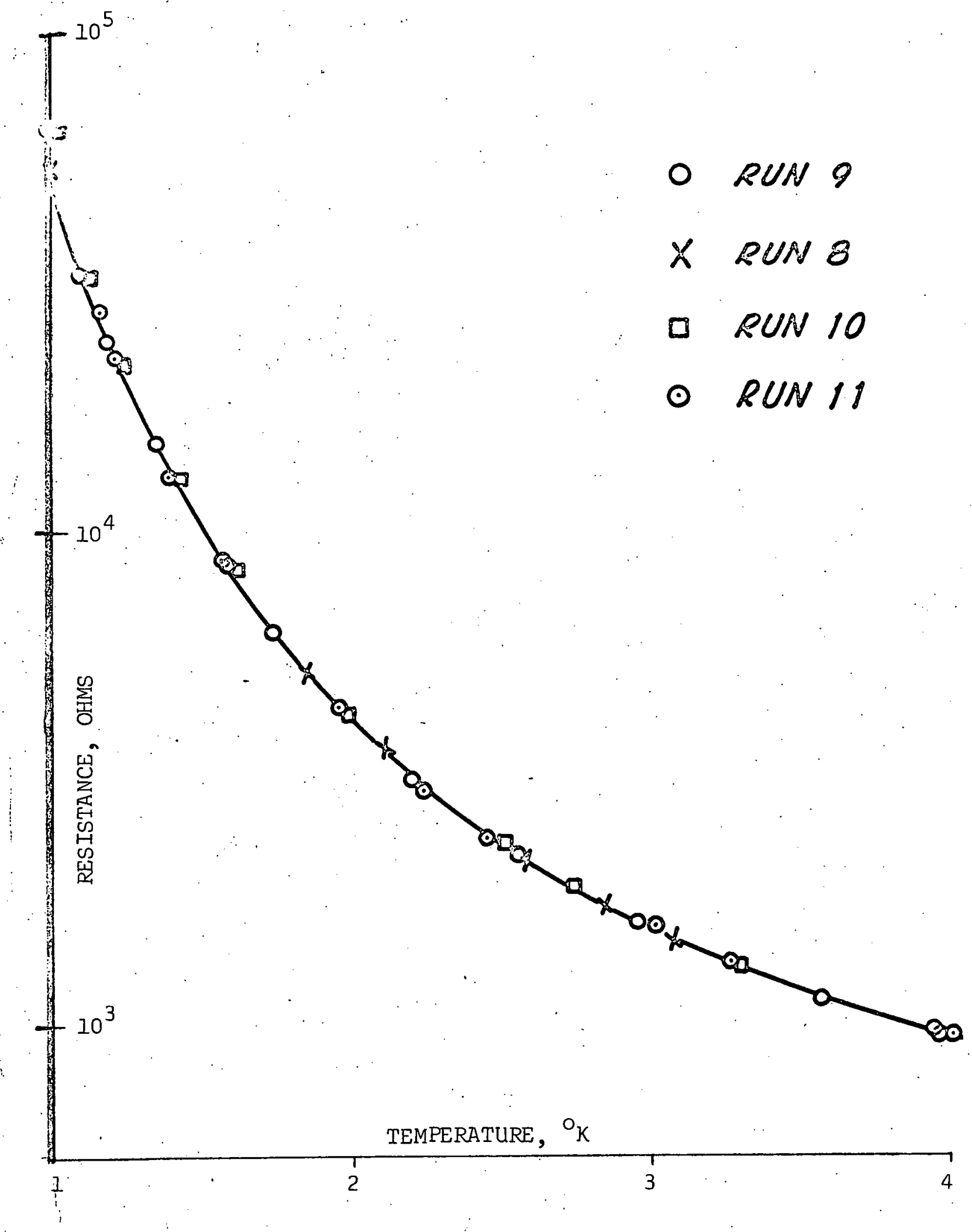

Fig. 6 Resistance vs. Temperature Calibration Curve for $1 / 10$ Watt Carbon Composition Resistor, 68 Ohms Nominal Resistance 
The low temperature end of the calibration curve of the 12 ohm resistor, Fig. 5, was subsequently corrected by re-calibration against the paramagnetic susceptibility temperature, as described in Section II. 


\section{BIBLIOGRAPHY}

1. Zemansky, M. W. Heat and Thermodynamics. 4th ed., McGraw-Hill Book Co., New York, 1957.

2. Hall, J. A.. "The International Temperature Scale." Temperature, Its Measurement and Control in Science and Industry, Vol. 2, Reinhold Publishing Corp., New York, 1955, p. 115

3. Stimson, H. F. "The Text Revision of the International Temperature Scale of 1948." Temperature, Its Measurement and Control in Science and Industry, Vol. 3 Part I, Reinhold, New York, 1962, p. 59

4. Borovick-Romanov, A. C.; P. G. Strelkov, M. P. Orlova and D. N. Astrov, "The I.M.P.R. Temperature Scale for the 10 to $90^{\circ} \mathrm{K}$ Region." Temperature, Vol. 3 Part 1, Reinhold, New York, 1962, p. 113

5. Scott, R. B. "Low. Temperature Scales from $90^{\circ}$ to $5^{\circ} \mathrm{K}$." Temperature, Vol. 2, Reinhold, New York, 1955, p. 179

6. Moessen, G. W., J. G. Aston and R. G. Ascah. "The Pennsylvania State University Thermodynamic Temperature scale below $90^{\circ} \mathrm{K}$ and the Normal Boiling Points: of Oxygen and Normal Hydrogen on the Thermodynamic Scale." Temperature, Vol. 3 Part 1, Reinhold, New York, 1962, p. 90

7. Hudson, R. P. "The Helium Vapor-Pressure Scale of Temperature." Temperature, Vol. 2, Reinhold, New York, 1955, P. 185

8. Clement, J. R. "The $1958 \mathrm{He}^{4}$ Temperature Scale." Temperature, Vol. 3 Part 1, Reinhold, New York; 1962, D. 67

9. Abraham, B. M., D. W. Osborne and B. Weinstock. "The Vapor Pressure, Critical Point, Heat of Vaporization, and Entropy of Liquid $\mathrm{He}^{3}$. Physical Review, 80 (1950), p. 366

10. Sydoriak, S. G. and T. R. Roberts. "Thermodynamic Properties of Liquid Helium Three. Vapor Pressures Below 1 $K$." Physical Review, 106 (1957), P. 175 
11. Roberts, T. R. and S. G. Syģoriak. "Thermomolecular Pressure Ratios for $\mathrm{He}^{3}$ and $\mathrm{He}^{4}$." Physical Review, 102 (1956), p. 304.

12. Kittel, C. Introduction to Solid State Physics. 2nd ed., John Wiley and Sons, Inc., New York, 1956, p. 212.

13. De Klerk, D. "Adiabatic Demagnetization:" Handbuch der Physik, Vol. 15, Springer, Berlin, 1956, 38-209.

14. Ambler, E: and R. P. Hudson. "Absolute Temperatures below $I^{\circ} \mathrm{K}$ : Chromic Methylammonium Alum as a Thermometric Substance." Journal of Chemical Physics, 27 (1957), P. 378 .

15. Mendoza, E. "Magnetic Cooling." Experimental Cryophysics. Butterworths, London, 1961, p. 167.

16. Daniels, J. M. and F. N. H. Robinson. "Cerium Magnesium Nitrate. II. Determination of the Entropy - Absolute Temperature Relation below 1 K.". Philosorhical Magazine, 44 (1953), p. 630.

17. Hull, J. R. and R. A. Hull. "Tables of Thermodynemic Functions of Paramagnetic Substances and Harmonic Oscillators." Journal of Chemical Physics, 9 (1941) p. 465 .

18. De Klerk, op. Clᄃ., P. 117.

19. Hudson, R. P., R..S. Kaeser and H. E. Radford. "Low Temperature Properties of Cerous Magnesium Nitrate." Proceedings of the 7 th International Conference on Low Temperature Physics. University of Toronco Press, Toronto, 196I, p. 100.

20. Hudson R. P. "The Thermodynamic Scale of Temperature below $I^{0}$." Temperature, Vol 3, Part 1, Reinhold, New York, 1962, p. 51 .

21. Hodgman; C., ed.; Handbook of Chemistry and Physics. 4lst. ed., Chemical Rubber Publishing Co., Cleveland, 1959, .p. 600 .

22. Sommerfeld, A. Electrodynamics. Academic Press, Inc. New York, 1952, P. 91.

23. Guenther, R. A. Unpublished Ph.D. Thesis, Illinois Institute of Technology, 1969. 
24. Abel, W. R., A. C. Anderson and J. C. Wheatley. "Temperature Measurements Using Small Quantities of Cerium Magnesium Nitrate." Review of Scientific Instruments, 35 (1964) p. 444.

25. Powell, R. L. and W. A. Blanpied. Thermal Conductivity of Metals and Alloys at Low Temperatures. National Bureau of Standards Circular 556, Sept. 1, 1954, U. S. Govt. Printing Office, Washington, D. C.

26. Stewart, R. B. and V. J. Johnson, eds. A Compendium of the Properties of Materials at Low Temperature (Phase II), Part IV, W.A.D.D. Technical Report 60-56, December, 1961, Aeronautical Systems Division, U. S. Air Force.

27. Maxwell, E. "Mutual Inductance Bridge for A. C. Susceptibility Measurements at Low Frequencies" Review of Scientific Instruments, 36 (1965) p. 553.

28. Lindenfeld, P. "Carbon and Semiconductor Thermometers For Low Temperatures." Temperature, Vol. 3 Part 1, Reinhold, New York, 1962, p. 399.

29. Clement, J. R., R. L. Dolecek and J. K. Logan. "Resistance Temperature 'Scaling' of Carbon Composition Thermometers." Advances in Cryogenic Engineering, Vol. 2, Plenum Press, New York, 1960, p. 104.

30. Edlow, M. H. and H. H. Plumb "Resistance Thermometry in the Liquid Helium Temperature Region." Temperature, Vol. 3 Part 1, Reinhold, New York, 1962, f. 407. 